\title{
IdeAs
}

Idées d'Amériques

16 | 2020

Les marges créatrices : intellectuel.le.s afrodescendant.e.s et indigènes auX Amériques, XIX-XXe siècle

\section{As margens criativas: intelectuais afro- descendentes e indígenas nas Américas, séculos XIX e XX}

Silvia Capanema, Véronique Hébrard, Fatma Ramdani e Claire Parfait

Tradutor. Silvia Capanema

\section{OpenEdition}

\section{Journals}

Edição electrónica

URL: http://journals.openedition.org/ideas/9947

ISSN: 1950-5701

\section{Editora}

Institut des Amériques

Refêrencia eletrónica

Silvia Capanema, Véronique Hébrard, Fatma Ramdani e Claire Parfait, « As margens criativas: intelectuais afro-descendentes e indígenas nas Américas, séculos XIX e XX », IdeAs [Online], 16 | 2020, posto online no dia 01 outubro 2020, consultado o 03 novembro 2020. URL : http:// journals.openedition.org/ideas/9947

Este documento foi criado de forma automática no dia 3 novembro 2020.

\section{$(1) \Theta \Theta$}

IdeAs - Idées d'Amériques est mis à disposition selon les termes de la licence Creative Commons Attribution - Pas d'Utilisation Commerciale - Pas de Modification 4.0 International. 


\title{
As margens criativas: intelectuais afro-descendentes e indígenas nas Américas, séculos XIX e XX
}

\author{
Silvia Capanema, Véronique Hébrard, Fatma Ramdani e Claire Parfait \\ Tradução : Silvia Capanema
}

Este número da revista IdeAs teve origem em um ateliê organizado em 2019 no âmbito do Congresso do Instituto das Américas intitulado « As margens criativas: a emergência de intelectuais negro/a/s e mestiço/a/s nas Américas (séculos XIX-XX)». O ateliê representava uma continuação de um primeiro trabalho sobre o poder criativo das margens, efetuado no quadro de uma chamada para projetos da Sorbonne Paris Cité: «Escrever a história a partir das margens: o caso dos africanos-americanos " $^{1}$. Elaborado por três professoras-pesquisadoras da Universidade Sorbonne Paris Nord (Claire Parfait), da Universidade de Paris (Marie-Jeanne Rossignol) e da Universidade Sorbonne Nouvelle-Paris 3 (Hélène Le Dantec-Lowry), o projeto demonstrou de que forma os historiadores africanos-americanos do século XIX e da primeira metade do século XX, situados à margem de suas sociedades, das instituições produtoras de pensamento e das redes editoriais, produziram verdadeiros tesouros de imaginação e astúcia. Tanto na busca de fontes, quanto na adoção de fórmulas alternativas para publicar e divulgar seus trabalhos, tais historiadores inovaram e sua situação marginal se mostrou, de fato, criativa.

o presente número amplia, assim, a questão a outras áreas geográficas e culturais, a outras margens, propondo estudar o conjunto das Américas - América Latina, Caribe e América do Norte -, para explorar a riqueza potencial de uma abordagem comparativa. Consideram-se os atores negros, "mestiços » ou autóctones, conforme a terminologia de cada país ou área compreendida ${ }^{2}$. Neste número, são incluídas também as dimensões de gênero e, mesmo se algumas contribuições se interessam pelo/a/s historiadores/ historiadoras, o enfoque principal são os processos de criação e de difusão a partir das margens. Compreende-se portanto aqui «intelectual» em sua ampla acepção, agrupando os pensadores (dentre os quais os/as historiadore/a/s), artistas e escritore/ 
$\mathrm{a} / \mathrm{s}^{3}$, mas também autodidatas e militantes. Não se trata portanto de experts, mas, sobretudo, parafraseando a definição de Pascal Ory e Jean-François Sirinelli, de homens e mulheres do meio cultural, criadores e mediadores ${ }^{4}$.

3 Este número não pretende, contudo, ser um inventário exaustivo da questão, mas propor uma série de estudos de casos, até mesmo porque alguns países se encontram mais representados que outros, como é o caso do Brasil. Nosso objetivo é propor pistas para se explorar a questão do poder criativo das margens. Como o próprio conceito de intelectual, cuja definição está sujeita ao debate, também a noção de margem merece ser problematizada. A marginalidade de que falamos pode ser de gênero, racial, étnica, social, espacial, econômica, profissional, política, cultural, acadêmica. Ela pode ser considerada como algo negativo, sinônimo de exclusão, de relegação, mas pode também ser percebida como lugar de criação. Como observa Michel Wieviorka:

As ciências sociais deploram há tempos as abordagens ambivalentes ou contraditórias com relação às margens ou à marginalidade. As mais clássicas enxergam nelas um conjunto de problemas, de dificuldades, que afetam certas pessoas, certos grupos, ou que constituem uma ameaça para a sociedade. Elas se interrogam sobre a origem, a produção ou as fontes desses problemas e dificuldades. Mas outras abordagens lançam um outro e novo olhar sobre as margens e a marginalidade, e se interrogam, quase de maneira inversa, sobre sua relação com a sociedade, ou com o mundo, suas normas, mas também sua criatividade, sua vitalidade, seu dinamismo ${ }^{5}$.

4 A experiência da América do Norte, dos Estados Unidos e do Canadá, a partir da contribuição do/a/s historiador/e/a/s negro/a/s, representa um primeiro nível de contribuição combinando marginalidade e originalidade de criação, como forma de contornar as margens, mas também de responder de outra maneira às questões da sociedade, a partir de um outro lugar de experiência. Todavia, pensar as margens nos leva a refletir sobre a existência de condições que podem ser duplamente, ou triplamente, marginais: pertencer a uma sociedade marginal na ordem ocidental mundial (América Latina, por exemplo) e estar à margem no interior dessa sociedade, por razões de pertencimento racial, de gênero, ou de condição social.

Deslocar o olhar do centro para a margem está no coração dos debates dos estudos póscoloniais, elaborados em particular no mundo anglo-saxônico ${ }^{6}$, mas também das correntes de pensamento decoloniais que têm origem em grande parte na América Latina ou no Canadá. A emergência dessas e desses intelectuais das margens, em diferentes espaços e épocas dos mundos americanos, possibilita colocar em diálogo essas perspectivas, em maior ou menor medida presentes nos diferentes artigos do dossiê. A articulação entre gênero, raça e classe se encontra, assim, no centro das análises. A criação intelectual - seja ela literária, científica ou artística - é o elemento que permite essa descentralização e a produção do novo, da escrita da história do/a/s esquecido/a/s, ou ao menos da história e dos escritos alimentados por experiências vividas à margem ou como tais. Disso surge a plasticidade dessa noção de margem, que não é somente geográfica, nem inscrita num território e delimitada por uma fronteira, mas também simbólica.

6 Os intelectuais que se encontram à margem são verdadeiros "passadores culturais " que realizam essa transfiguração dos sentidos, às vezes como experiências concretas dos fenômenos de crioulização ${ }^{7}$, descritos, por exemplo, no artigo de Maud Delevaux sobre o poeta afro-peruano Nicomedes Santa Cruz. 
7 Quando os ameríndios escrevem a sua história e se tornam, de forma deliberada, « intelectuais indígenas », produzem não somente excelentes estudos, mas propõem também uma nova epistemologia, como nos textos de Stéphanie Boutevin sobre a visão autóctone no Canadá, e na análise de Lionel Larré sobre a reconquista da soberania intelectual dos índios nos Estados Unidos. Os intelectuais indígenas encontram-se na origem de projetos inovadores em matéria de práticas culturais e de educação, como demonstra o artigo de Elena Nava sobre a criação da "comunalidad", uma experiência dos intelectuais indígenas do Estado de Oaxaca no México dos anos 1980, retomada por outros atores contemporâneos nos meios universitários e culturais. Luiz Henrique Eloy Amado, ele próprio um «intelectual indígena », explora as mutações profundas nas ciências humanas quando os índios entram nas universidades e partem para fazer pesquisa de campo. Os índios não são mais meros « objetos de pesquisa », mas tornamse igualmente produtores do conhecimento científico, modificando as formas de pensar de seus contemporâneos.

8 Uma operação similar ocorre com os intelectuais negros, tema do texto de Claire Parfait, através da história - durante muito tempo "esquecida - de Joel Augustus Roger, historiador negro norte-americano da primeira metade do século XX que se insere, mesmo se de forma diferente, numa longa tradição de historiadores negros. Fatma Ramdani estuda por sua vez uma mulher historiadora africana-americana, Mary Church Terrell, que no final do século XIX e no início do XX, escreve ensaios de uma autobiografia buscando reivindicar um lugar para o testemunho das mulheres negras na narrativa de uma América segregada.

9 As mulheres, por vezes em posição de dupla ou tripla marginalidade (mulheres, racializadas, pobres), são agentes de transgressão literária ou política. Elas produzem uma nova estética mas são testemunhas também de um engajamento transformador, como demonstra o artigo de Grégory Bekhtari sobre a ação política e sindical das mulheres negras, empregadas domésticas nos Estados Unidos na metade do século XX, cujas lutas são transmitidas pela corrente do Black Left Feminism. Elas transformam sua condição marginal em motor para a vanguarda política e cultural.

10 As mulheres negras intelectuais se tornam escritoras de sua história e ao mesmo tempo fontes de primeira ordem para uma outra história. Elas criam novas estéticas literárias, como demonstra Silvia Capanema em sua análise cruzada dos textos de Carolina Maria de Jesus e Conceição Evaristo sobre suas experiências nas favelas brasileiras do século $\mathrm{XX}$. Essa relação entre nova estética literária e fontes para a história surge também na escrita de Estercilia Simanca Pushaina, revelando estratégias de negociação da comunidade indígena wayuu na península de La Guajira, entre a Colômbia e a Venezuela, como propõe o trabalho de Laura Lema Silva. A escolha pela língua dominante, o espanhol, obedece, nesse sentido, a uma vontade deliberada de diálogo com a sociedade colombiana, bem como de transmissão.

11 Da mesma forma, as mulheres indígenas intelectuais utilizam a escrita para marcar seu engajamento e transmitir suas tradições, como mostra o ensaio de Fabrice Le Corguillé a partir do estudo do caso de Sarah Winnemucca, nos Estados Unidos do século XIX.

12 Nádia Maria Cardoso da Silva discute as estratégias de negociação e de afirmação de dois intelectuais negros brasileiros invisibilizados, Virginia Leone Bicudo e Guerreiro Ramos. Ambos, devido à sua situação marginalizada, são precursores de um pensamento decolonial antes do tempo. De maneira similar, o escritor C. L. R. James, em sua juventude caribenha, rompe com a lógica colonialista e propõe, desde os anos 1920, 
uma leitura que "provincializa a Europa », para retomar a expressão formulada pelo historiador Dipesh Chakrabarty em $2000^{8}$.

Valmir Luis Saldanha da Silva analisa no tempo longo a criação literária dos afrodescendentes no Brasil, desde escritores consagrados - como Machado de Assis e Gonçalves Dias - até o grupo de rap Racionais Mc. Demonstra assim que é precisamente na descentralização, na transformação do centro em periferia, que reside a principal contribuição do poder criador das margens.

14 Tal movimento de deslocamento dos sujeitos periféricos para o centro encontra-se também no coração da análise do intelectual universitário africano radicado no Brasil, Kabengele Munanga (artigo de Reinaldo José de Oliveira e Regina Marques de Souza Oliveira).

15 O descentramento dos lugares e dos olhares se torna, enfim, um elemento que permite a todo intelectual reinterpretar o mundo, como revela a análise, em guisa de conclusão do número, feita por Françoise Palleau-Papin da escrita de Ben Fountain, escritor norte-americano que utiliza o Haiti como espelho para os Estados Unidos.

Essas diferentes experiências de criação a partir das margens com múltiplas declinações nos mundos americanos são o objeto deste dossiê temático. Uma vez que todos os intelectuais evocados neste número são ao mesmo tempo observadores $\mathrm{e}$ atores, e sempre engajados, o dossiê nos convida a pensar nas relações entre marginalidade e militantismo. Ele convida-nos, além disso, a nos interrogarmos sobre a pertinência dos conceitos de centro e de periferia. Com efeito, será que o conceito de margem teria ainda sentido num momento em que as noções de história cruzada ou conectada e de circulação substituem as de história nacional e de transferências, tornando a oposição entre « centro » e " periferia » sem dúvida menos pertinente?

\section{NOTAS}

1. Ver https://hdlm.hypotheses.org/ e as publicações associadas: Writing History from the Margins: African Americans and the Quest for Freedom, sob a direção de Claire Parfait, Hélène Le DantecLowry e Claire Bourhis-Mariotti (New York: Routledge, 2017) ; Ecrire l'histoire depuis les marges: une anthologie d'historiens africains-américains 1855-1865, na coleção SHS das éditions Terra-HN, 2018 : http://www.shs.terra-hn-editions.org/Collection/?-Historiens-africains-americains-; Histoire en marges. Les périphéries de l'histoire globale, editado por Hélène Le Dantec-Lowry, Matthieu Renault, Marie-Jeanne Rossignol e Pauline Vermeren, Tours, Presses universitaires François-Rabelais, 2018.

2. Retomando as palavras de Pap Ndiaye, «As raças não existem enquanto tais, mas elas são categorias imaginárias historicamente construídas... A noção de mestiço não tem mais validade científica que a noção de raça, uma vez que ela supõe a existência prévia de raças puras. Devemos compreendê-la portanto em um sentido histórico e social. » Pap N 'Diaye, "Controverse, Pour une histoire des populations noires en France : préalables théoriques ", Le Mouvement Social, $\mathrm{n}^{\circ}$ 213, outubro-dezembro 2005: 91-108. Sobre esse tema, ver também Magali Bessone, Sans 
distinction de race? Une analyse critique du concept de race et de ses effets pratiques, Paris, Vrin, «Philosophie concrète ", 2013.

3. Esta definição de intelectuais é de Vincent Duclert, que alerta todavia para o fato de que ela é « limitativa »: Vincent Duclert, «Les intellectuels, un problème pour l'histoire culturelle », Les Cahiers du Centre de Recherches Historiques [En ligne], 31|2003, em linha em 15 de setembro de 2008, consultado em 02 de setembro de 2020. URL: http://journals.openedition.org/ccrh/293 ; DOI : https://doi.org/10.4000/ccrh.293

Lembremos aliás que a definição da palavra intelectual varia conforme os lugares e as épocas, como observa François Dosse : «Podemos então afirmar que a noção de intelectual é polissêmica, que ela cobre concepções diferentes segundo os períodos e áreas culturais »: François Dosse, «Introduction», La marche des idées: Histoire des intellectuels, histoire intellectuelle, Paris, La Découverte, 2012.

4. Pascal Ory e Jean-François Sirinelli, Les intellectuels en France. De l'affaire Dreyfus à nos jours, Paris, Armand Colin, 1986, p. 5. Eles acrescentam que este « homem da cultura » é « posto em situação de homem político, criador ou consumidor de ideologia. » (Ibid.).

5. Michel Wieviorka, "Ce que sont les marges aux sciences sociales », Conferência inaugural do Colóquio internacional «La reconnaissance des marges, au cœur des dynamiques sociales en France et au Japon ", $1^{\text {er }}$ juillet 2016 - Maison Franco-japonaise de Tokyo: https:// wieviorka.hypotheses.org/706

6. Ver : Achille Mbembe, «Qu'est-ce que la pensée postcoloniale ? (Entretien) », Esprit [En ligne], mars 2019, consultado em 27 de setembro de 2020. Ver também Edward W. Said, Orientalism, New York, Pantheon Books, c. 1978 ; Paul Gilroy, The Black Atlantic: Modernity and Double Consciousness, London, Verso, 1993.

7. Édouard Glissant, Introduction à une poétique du Divers, Paris, Gallimard, 1996.

8. Chakrabarty, Dipesh. Provincializing Europe: Postcolonial Thought and Historical Difference. Princeton, Oxford, Princeton University Press, 2000.

\section{AUTORES}

\section{SILVIA CAPANEMA}

Docteure en Histoire par l'EHESS, Paris, Maîtresse de conférences à l'Université Paris 13 -

Sorbonne Paris Nord

\section{VÉRONIQUE HÉBRARD}

Véronique Hébrard est Professeure d'histoire et civilisation de l'Amérique latine contemporaine à l'Université de Lille. Ses travaux portent sur l'histoire politique du Venezuela au XIX ${ }^{\mathrm{e}}$ siècle et plus spécifiquement sur les processus de mobilisation et de politisation des populations civiles en temps de guerre. Sur ces questions elle a notamment publié «Ciudades leales, ciudades patriotas. Guerra de independencia y identidades urbanas (Venezuela, siglo XIX) », Tiempo y Espacio (Caracas), n 63, enero-junio 2015, p. 163-186; 21; « Justicia “excepcional” y lógicas de radicalización durante la primera Pacificación de Venezuela (1812-1814) », Revista de Indias, 2016, vol. LXXVI, no 266 , p. 17-50.Elle s'intéresse également aux archives des américanistes français, sur lesquelles elle a publié : Véronique Hébrard (dir.), Por una concepción atlántica del americanismo. En los pasos de François Chevalier, Paris, Editions des Archives Contemporaines, 2013 ; Véronique 
Hébrard (dir.), Sur les traces d'un mexicaniste français. Constitution et analyse du fonds François Chevalier, Paris, Karthala, collection Pollens, 2005.

\section{FATMA RAMDANI}

Fatma Ramdani est maîtresse de conférences à l'Université de Lille en histoire des États-Unis. Ses travaux portent sur les mouvements féministes américains dans leur dimension internationale. Elle s'intéresse à la contribution des Africaines-Américaines dans l'écriture de l'histoire. Ses travaux s'interrogent sur les questions de transmission et de mémoire. A titre d'exemple, a publié « Mary McLeod Bethune (1875-1955), historienne africaine américaine oubliée », dans Histoire en marges, Les périphéries de l'histoire globale, ed. Hélène Le Dantec-Lowry et al., Presses Universitaires François Rabelais, 2018.

\section{CLAIRE PARFAIT}

Claire Parfait est affiliée à la Pléiade, Université Sorbonne Paris Nord 